\title{
Characteristics of volumetric losses and efficiency of axial piston pump with respect to displacement conditions*
}

\author{
Bing XU $\mathrm{XU}^{\dagger}$, Min HU, Jun-hui ZHANG, Qi SU \\ (The State Key Laboratory of Fluid Power and Mechatronic Systems, Zhejiang University, Hangzhou 310027, China) \\ †E-mail: bxu@zju.edu.cn \\ Received July 3, 2015; Revision accepted Oct. 28, 2015; Crosschecked Feb. 15, 2016
}

\begin{abstract}
A good efficiency performance of a pump over a wide range of displacement conditions is crucially important for variable pump control systems to save energy. However, according to the literature, less attention has been paid to the understanding of the efficiency, leakage flow, and compression flow characteristics of the pump with respect to displacement conditions. In this study, a test bench was built, and a novel explicit volumetric loss model was proposed to investigate these problems. The overall efficiency is found to drop considerably with the decreasing displacement. The volumetric losses range from $13 \%$ to $47 \%$ of the total power losses of pump at the rated speed, under the conditions of pressure ranging from 5 to $35 \mathrm{MPa}$ and displacement ranging from $13 \%$ to $100 \%$ of full displacement. The highest proportion of compression flow losses in the total volumetric losses of pump at the rated speed can reach up to $41 \%$ when the pressure and displacement are greater than $30 \mathrm{MPa}$ and $88 \%$ of full displacement, respectively; after that, the proportion gradually decreases with decreasing displacement. However, the leakage flow generally increases with decreasing displacement, or may decrease first and begin to increase after the minimum with the further decrease of displacement. In the components of leakage of slipper/swash plate pair, the squeeze leakage is found to reach a magnitude equal to that of the Poiseuille leakage. The findings can guide the further research and design of pumps with better efficiency performance.
\end{abstract}

Key words: Axial piston pump, Efficiency, Leakage, Compression flow, Displacement condition http://dx.doi.org/10.1631/jzus.A1500197

CLC number: TH13

\section{Introduction}

Efficiency performance is a major sales argument of axial piston pumps today in a majority of industrial markets. Volumetric losses are one of the important factors responsible for efficiency decrease of a pump. Such losses can be generated in the lubricating gaps of pump, known as leakage flow losses, and in the pump displacement chamber, known as

\footnotetext{
* Project supported by the National Basic Research Program (973 Program) of China (No. 2014CB046403) and the National Key Technology R\&D Program of the Twelfth Five-year Plan of China (No. 2013BAF07B01)

(iD) ORCID: Bing XU, http://orcid.org/0000-0003-0236-7896

(C) Zhejiang University and Springer-Verlag Berlin Heidelberg 2016
}

compression flow losses. So far, a large number of studies related to the leakage flow in the lubricating gaps of pump have been carried out. The involved lubricating gaps in the pump include piston/cylinder interface, slipper/swash plate interface, valve plate/ cylinder interface, and piston/slipper spherical bearings.

Traditionally, Poiseulle equation and Couette equation are used to evaluate the leakage via piston/ cylinder interface (Ivantysyn and Ivantysynova, 2001; Ma et al., 2010b; Guan et al., 2014). A more precise way is via using the 2D Reynolds equation of lubrication (Xu et al., 2013; Mizell and Ivantysynova, 2014; Wegner et al., 2014; Lin and Hu, 2015). Pistons in some pumps often have several grooves cut along the axis in order to increase stability, decrease friction, and reduce lateral forces. Some attempts have been 
made to find the leakage flow theoretically taking into account the effect of grooves (Kumar and Bergada, 2013).

A detailed review and discussion on the study related to the leakage via slipper/swash plate interface since 1962 and cylinder/valve plate gap since 1974 was made by Bergada et al. (2012a). On the basis of the discussion of previous studies, they found that no study was performed on the slippers with nonvented grooves. Therefore, in their studies they carefully derived the equations to calculate the leakage via the slipper/swash plate interface, in which the slipper had non-vented grooves. They also derived the explicit equations to compute the leakage and pressure distribution between the cylinder and valve plate (Bergada et al., 2012a; 2012b).

The leakage of piston/slipper spherical bearing is very small compared with other leakages of the pump. Therefore, most of the studies done on the piston/ slipper spherical bearing are related to friction torque (Kazama, 2008). Recently, the equations for calculating the leakage through the piston/slipper spherical bearing were derived by Bergada et al. (2012a).

From the review of the previous studies, it can be found that studies on the leakage of each individual lubricating gap of the pump are specific. However, little attention has been paid to the variation characteristics of leakage flow of the pump versus the displacement conditions. With the fast development of the technology related to pump control system, variable displacement pumps are getting wider employment in various fields. Variable displacement pumps usually have to work under the displacement conditions varying within a large range, to improve the power matching between the pump and the load to save energy. Therefore, a deeper insight of the variation characteristics of various volumetric losses versus displacement conditions is indispensable. By reviewing the leakage equations derived in the previous studies, it can also be found that the previous equations to calculate the leakage via slipper/swash plate gap, which is the uppermost leakage source directly related to the displacement conditions, are merely linked with the differential pressure effect. However, there are other factors affecting the leakage, for instance, the micro squeezing motion of slipper, the spin motion of slipper, etc. Therefore, a deeper insight into the leakage mechanism of slipper/swash plate pair is necessary.

According to the literature, the compression flow characteristic of pump over wide operating ranges is not fully known as well. A comparison of the flow ripple of pump, which was simulated from a verified model with compressible and incompressible fluids, was made by Ma et al. (2010a). The comparison shows that the flow ripple is one order of magnitude larger when the simulation employed the compressible hydraulic oil. The computation results with the compressible fluid better agree with the experimental results. Recently, the power losses due to compressibility of oil in the pump under two cases of full displacement conditions were measured by Zecchi et al. (2013). They found that the power losses due to oil compressibility at full displacement conditions are an important source of power losses of a pump.

In this study, a series of experiment-based studies on the efficiency and losses of a typical axial piston pump over wide operating ranges are performed. Furthermore, a novel model capable of providing an explicit insight into the volumetric losses of pump is proposed to analyze the mechanism of leakage and deepen the understanding of the variation of volumetric losses with the displacement conditions.

\section{Simulation modeling}

A novel explicit volumetric losses model of a pump is developed, as shown in Fig. 1. The transient pressure of oil in a certain piston chamber can be represented by (Edge and Darling, 1989)

$$
\begin{gathered}
\frac{\mathrm{d} p_{\mathrm{c}}}{\mathrm{d} t}=\frac{q_{\mathrm{sp}} K_{\mathrm{e}}}{V_{\mathrm{c}}}, \\
q_{\mathrm{sp}}=q_{\mathrm{r}}-q_{\mathrm{i}}-q_{\mathrm{lp}}-q_{\mathrm{ls}}-q_{\mathrm{lv}},
\end{gathered}
$$

where $p_{\mathrm{c}}$ denotes the transient pressure of oil in piston chamber, $V_{\mathrm{c}}$ stands for the volume of oil in piston chamber, $q_{\mathrm{sp}}$ represents the flow rate via the single piston chamber, $q_{\mathrm{lp}}, q_{\mathrm{ls}}$, and $q_{\mathrm{lv}}$ denote the leakage flow of piston/cylinder pair, slipper/swash plate pair, and valve plate/cylinder pair, respectively, $q_{\mathrm{i}}$ is the discharge and intake flow, and $q_{\mathrm{r}}$ denotes the flow rate generated by the reciprocating motion of piston, as 
Eq. (3) describes. The compressibility of oil is considered by the elastic modulus of the oil, $K_{\mathrm{e}}$.

$$
q_{\mathrm{r}}=A_{\mathrm{p}} v_{\mathrm{p}},
$$

where $A_{\mathrm{p}}$ is the piston crosssection area, $v_{\mathrm{p}}$ stands for the velocity of piston, derived from the dynamics module, which models the kinematics and dynamics of the pump parts, and transmits the kinematics parameters to the hydraulic module in real time, including the displacement $d_{\mathrm{vdp}}$ and the velocity $v_{\mathrm{vdp}}$ of the stroking piston, as well as the velocity of each piston. The stroking piston module supplies the driving force for the variable displacement piston of the pump in dynamics module to achieve different displacement conditions.

Expression for modeling the discharge and intake flow represented by the variable $q_{\mathrm{i}}$ in Eq. (2) for the piston might be given by the classical orifice equation, which is based on the Bernoulli principle, described in a form of (Manring, 2000; Ericson and Palmberg, 2012; Mandal et al., 2012; Huang et al., 2014; Xu et al., 2015a; 2015b)

$$
q_{\mathrm{i}}=C_{\mathrm{r}} A_{\mathrm{r}} \sqrt{2\left|p_{\mathrm{kp}}-p_{\mathrm{c}}\right| / \rho} \cdot \operatorname{sign}\left(p_{\mathrm{kp}}-p_{\mathrm{c}}\right),
$$

where $C_{\mathrm{r}}$ is the discharge coefficient, $\rho$ is the oil density, and $p_{\mathrm{kp}}$ is the pressure in the kidney port, which repeatedly changes between the discharge pressure and intake pressure with the cylinder block rotating around the shaft. The flow area $A_{\mathrm{r}}$, which is integrated in the hydraulic module as valve plate model shown in Fig. 1, is described by a piecewise function divided into eight sections. The flow area over one revolution of shaft is portrayed in Fig. 2, where ODC is the outer dead center.

On the basis of the clearance flow theory between two parallel disks, the leakage flow via the constant valve plate/cylinder gap can be derived as

$$
q_{\mathrm{lv}}=\frac{\alpha_{\mathrm{f}} \delta_{\mathrm{v}}^{3}}{12 \mu}\left[\frac{1}{\ln \left(R_{2} / R_{1}\right)}+\frac{1}{\ln \left(R_{4} / R_{3}\right)}\right]\left(p_{\mathrm{c}}-p_{0}\right)
$$

where $\alpha_{\mathrm{f}}$ is the angle of the complete opening of the outlet opening in valve plate, $\delta_{\mathrm{v}}$ is the oil film depth

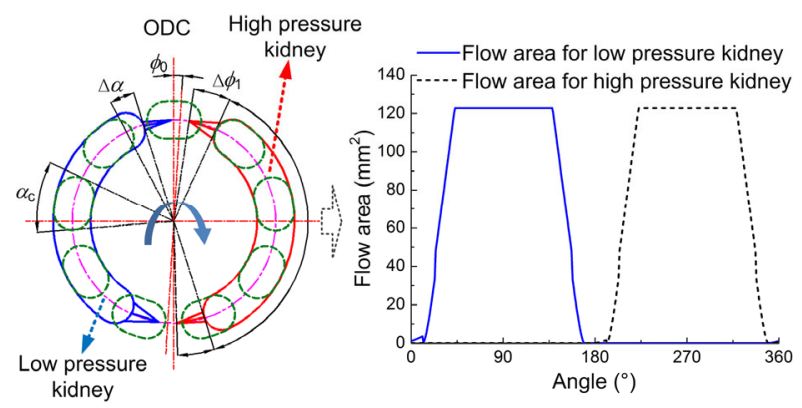

Fig. 2 Variation of flow area

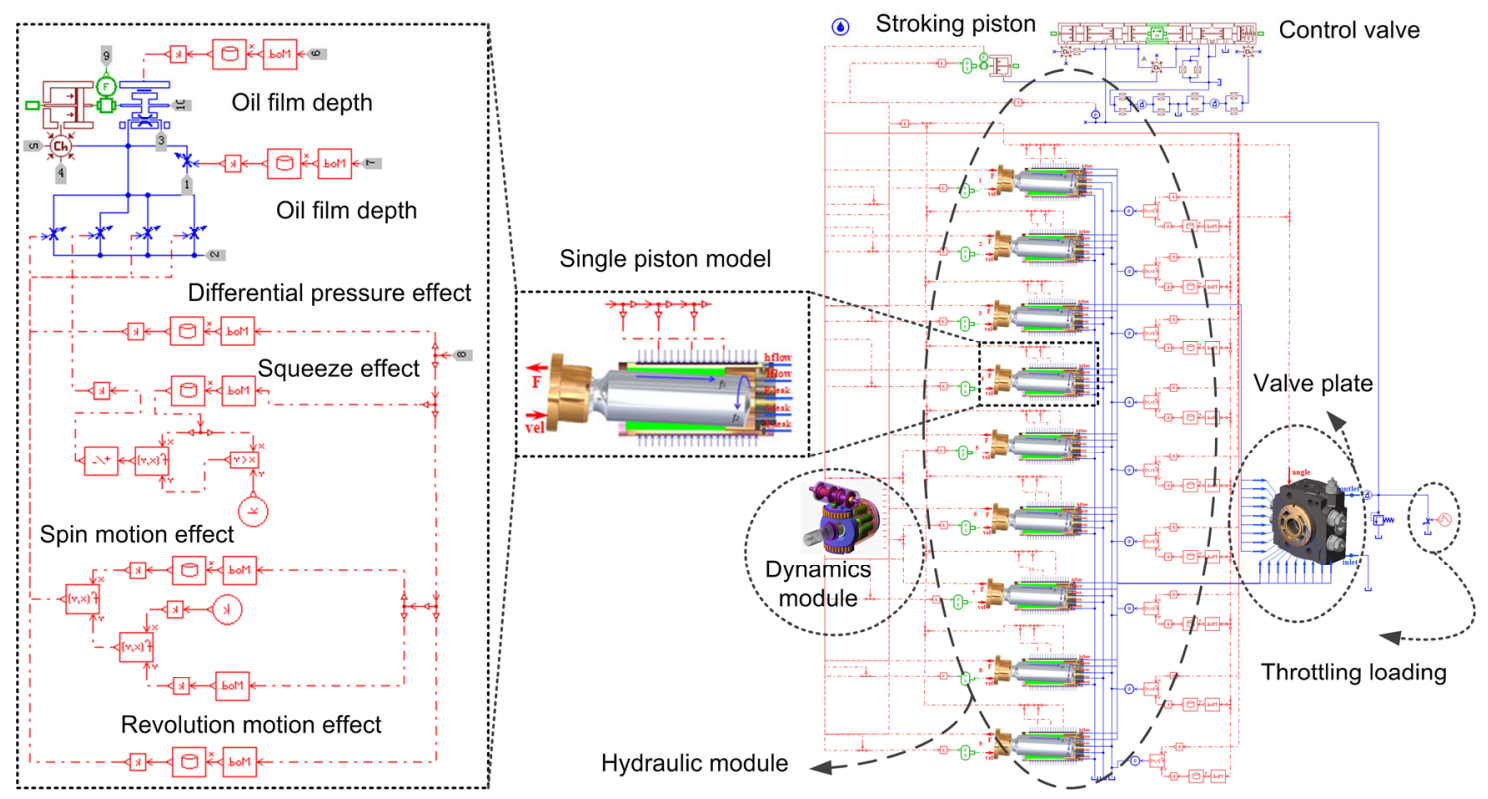

Fig. 1 Explicit volumetric losses model of the pump 
of valve plate/cylinder pair, $R_{1}, R_{2}, R_{3}$, and $R_{4}$ are the structure parameters of valve plate, $\mu$ is the dynamic viscosity of oil, and $p_{0}$ is the pressure of oil in the pump case.

The variation of pump displacement conditions directly influences the leakage flow via the piston/ cylinder gap and slipper/swash plate gap. Therefore, the considerable emphasis in this study is mainly placed on the leakage of the piston/cylinder pair and slipper/swash plate pair. The leakage via the piston/ cylinder gap is affected by the Poiseuille flow, which is linked with the differential pressure, and the Couette flow, which is linked with the piston velocity, as Eq. (6) describes:

$$
q_{\mathrm{lp}}=\frac{\pi d_{\mathrm{p}} \delta_{\mathrm{p}}^{3}}{12 \mu l_{\mathrm{p}}}\left(1+1.5 \varepsilon_{\mathrm{p}}^{2}\right)\left(p_{\mathrm{c}}-p_{0}\right)-\frac{\pi d_{\mathrm{p}} \delta_{\mathrm{p}} v_{\mathrm{p}}}{2}
$$

where $d_{\mathrm{p}}$ is the diameter of piston, $l_{\mathrm{p}}$ is the gap length between piston and bush, $\delta_{\mathrm{p}}$ is the oil film depth of piston/cylinder pair, and $\varepsilon_{\mathrm{p}}$ is the eccentricity of piston in cylinder bore.

The leakage flow via the slipper/swash plate gap consists of Poiseuille flow, Couette flow, and squeeze flow. The Poiseuille flow is linked with the differential pressure between slipper chamber and pump case; the Couette flow is linked with the revolution motion velocity and spin motion velocity of slipper; the squeeze flow is related to the squeeze velocity of the slipper.

The fluid continuity equation can be generally described in the form of Eq. (7), where $z$ stands for the direction of oil film depth of slipper/swash plate pair, and $r$ stands for the length in the radial direction.

$$
\frac{\partial v_{r}}{\partial r}+\frac{1}{r} \frac{\partial v_{\theta}}{\partial \theta}+\frac{\partial v_{z}}{\partial z}+\frac{v_{r}}{r}=0
$$

With the Navier-Stokes equation and fluid continuity equation, Eq. (8) can be derived, where $\omega_{\mathrm{sm}}$ is the spin angular velocity of the slipper, and $\delta_{\mathrm{s}}$ is the oil film depth of slipper/swash plate pair. More detail of the derivation procedure of Eq. (8) can be found in Appendix A.

$$
\frac{1}{\mu} \frac{\partial p}{\partial r}=\frac{\partial^{2} v_{r}}{\partial z^{2}}+\frac{\rho \omega_{\mathrm{sm}}^{2} r z^{2}}{\mu \delta_{\mathrm{s}}^{2}}
$$

Since the oil film depth is generally several micrometers, the variation of pressure in the direction of oil film depth is very small and can be neglected. Therefore, the pressure distribution of oil film of slipper/swash plate pair can be considered only a function of the variable $r$. The boundary condition of Eq. (8) can be described as

$$
\begin{cases}z=0, & v_{r}=0 \\ z=\delta_{\mathrm{s}}, & v_{r}=0 .\end{cases}
$$

By substituting the boundary condition shown in Eq. (9), Eq. (10) can be derived via the integration of Eq. (8) over the oil film depth:

$$
v_{r}=\frac{1}{2 \mu} \frac{\mathrm{d} p}{\mathrm{~d} r} z\left(z-\delta_{\mathrm{s}}\right)-\frac{\rho \omega_{\mathrm{sm}}^{2} r}{12 \mu}\left(\frac{z^{4}}{\delta_{\mathrm{s}}^{2}}-z \delta_{\mathrm{s}}\right)
$$

The flow rate of fluid film flowing via the clearance between slipper and swash plate in the radial direction can be derived by integrating Eq. (10) over the oil film depth along the circumferential direction, as shown as

$$
\begin{gathered}
q_{\mathrm{tem} 1}=\int_{0}^{\delta_{\mathrm{s}}} 2 \pi r v_{r} \mathrm{~d} z=q_{\mathrm{pde}}+q_{\mathrm{sme}}, \\
q_{\mathrm{pde}}=-\frac{\pi r \delta_{\mathrm{s}}^{3}}{6 \mu} \frac{\mathrm{d} p}{\mathrm{~d} r}, \\
q_{\mathrm{sme}}=\frac{\pi \rho \delta_{\mathrm{s}}^{3} \omega_{\mathrm{sm}}^{2} r^{2}}{20 \mu},
\end{gathered}
$$

where $q_{\text {pde }}$ is the Poiseuille flow, and $q_{\text {sme }}$ is the Couette flow caused by the centrifugal force of a certain representative elemental mass of oil film in the lubricating interface between the slipper and swash plate, due to the spin motion of slipper. Integrating Eq. (12) over the radius $r$ yields

$$
q_{\mathrm{pde}}=\frac{\pi \delta_{\mathrm{s}}^{3} \Delta p_{\mathrm{s}}}{6 \mu \ln \left(R_{\mathrm{s}} / r_{\mathrm{s}}\right)}
$$

where $\Delta p_{\mathrm{s}}$ stands for the differential pressure between slipper chamber and pump case, and $R_{\mathrm{S}}$ and $r_{\mathrm{s}}$ denote the radius of slipper and slipper chamber, respectively. Integrating Eq. (13) over the radius $r$ yields 


$$
q_{\mathrm{sm}}=\int_{r_{\mathrm{s}}}^{R_{\mathrm{s}}} q_{\mathrm{sme}} \mathrm{d} r=\frac{\pi \rho \delta_{\mathrm{s}}^{3} \omega_{\mathrm{sm}}^{2}}{60 \mu}\left(R_{\mathrm{s}}^{3}-r_{\mathrm{s}}^{3}\right)
$$

where $q_{\mathrm{sm}}$ is the leakage flow caused by the centrifugal force of oil film in the lubricating interface between slipper and swash plate, due to the spin motion of slipper.

As Fig. 3 shows, the slipper slides on the swash plate plane along an elliptical locus at the angular speed of $\omega_{\mathrm{rm}}$. The oil film in the clearance between slipper and swash plate is distributed in the annular area between the outer radius $R_{\mathrm{S}}$ and the inner radius $r_{\mathrm{s}}$ of the slipper. The oil film field is divided into four quadrants by the established coordinate system $o-x y$, as shown in Fig. 3, where $S_{1}, S_{2}, S_{3}$, and $S_{4}$ stand for the quadrants divided by the $o$-xy coordinate system.

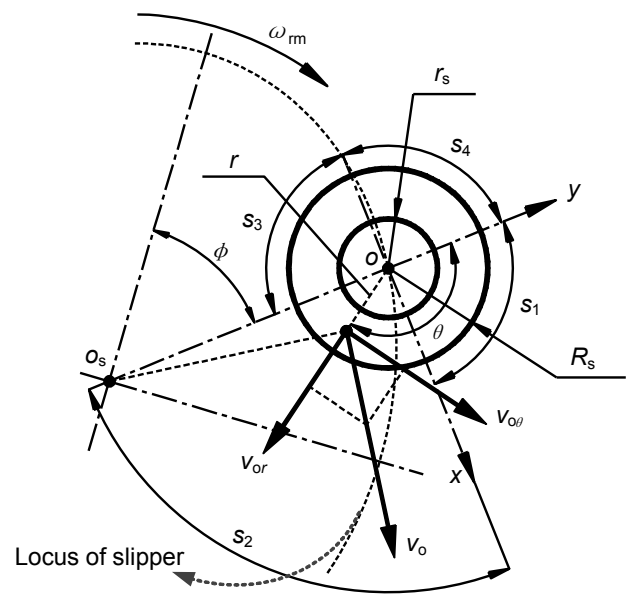

Fig. 3 Diagram for the derivation of Couette flow caused by the revolution motion of slipper

Taking a certain representative elemental volume $\mathrm{d} v$ of oil film as the analytical object, the corresponding tangential velocity $v_{0}$ of the representative elemental volume can be derived as (Xu et al., 2012)

$$
\begin{gathered}
v_{\mathrm{o}}=\frac{z \cos \beta \sqrt{l^{2}+r^{2}-2 l r \cos (\pi-\theta)}}{\delta_{\mathrm{s}}\left(\cos ^{2} \phi+\cos ^{2} \beta \sin ^{2} \phi\right)} \omega_{\mathrm{p}}, \\
l=R_{\mathrm{p}} \sqrt{\sin ^{2} \phi+\left(\frac{\cos \phi}{\cos \beta}\right)^{2}},
\end{gathered}
$$

where $l$ is the distance between the points $o_{\mathrm{s}}$ and $o, \omega_{\mathrm{p}}$ is the angular speed of pump, $\beta$ is the swash plate angle, $R_{\mathrm{p}}$ is the pitch circle radius of piston, and $\phi$ is the angular position of shaft. The radial velocity component $v_{\mathrm{o} r}$ of the representative elemental volume is derived from Eq. (16) as

$$
v_{\mathrm{o} r}=v_{\mathrm{o}} \sin \theta
$$

The Couette flow caused by the revolution motion of slipper can be derived by the integration of the radial velocity of the representative elemental volume over the total volume of oil film field, as shown by Eq. (19), where the subscripts 1, 2, 3, and 4 stand for the number of quadrants, as shown in Fig. 3.

$$
\begin{aligned}
q_{\mathrm{rm}} & =\int_{r_{\mathrm{s}}}^{R_{\mathrm{s}}} \int_{z=0}^{\delta_{\mathrm{s} 1}} \int_{\theta=0}^{\pi / 2} v_{\mathrm{or} 1} \mathrm{~d} r \mathrm{~d} z \mathrm{~d} \theta \\
& +\int_{r_{\mathrm{s}}}^{R_{\mathrm{s}}} \int_{z=0}^{\delta_{\mathrm{s}}} \int_{\theta=\pi / 2}^{\pi} v_{\mathrm{or} 2} \mathrm{~d} r \mathrm{~d} z \mathrm{~d} \theta \\
& +\int_{r_{\mathrm{s}}}^{R_{\mathrm{s}}} \int_{z=0}^{\delta_{\mathrm{s}}} \int_{\theta=\pi}^{3 \pi / 2} v_{\mathrm{or} 3} \mathrm{~d} r \mathrm{~d} z \mathrm{~d} \theta \\
& +\int_{r_{\mathrm{s}}}^{R_{\mathrm{s}}} \int_{z=0}^{\delta_{\mathrm{s}}} \int_{\theta=3 \pi / 2}^{2 \pi} v_{\mathrm{or} 4} \mathrm{~d} r \mathrm{~d} z \mathrm{~d} \theta .
\end{aligned}
$$

For a certain representative annular elemental area $2 \pi r \mathrm{~d} r$ of the oil film, the initial flow rate without squeezing is described by Eq. (12). However, actually due to the squeezing movement of slipper, the squeezed oil film will give rise to a variation of the flow rate, which can be calculated by Eq. (20) derived from Eq. (12):

$$
\mathrm{d} q=-2 \pi d\left(\frac{\delta_{\mathrm{s}}^{3}}{12 \mu} r \frac{\mathrm{d} p}{\mathrm{~d} r}\right)
$$

The variation of the flow rate is equal to the extrusion flow along the annular surface of the representative annular elemental area $2 \pi r \mathrm{~d} r$ of oil film, given by

$$
2 \pi r \mathrm{~d} r\left(-\frac{\mathrm{d} \delta_{\mathrm{s}}}{\mathrm{d} t}\right)=-2 \pi d\left(\frac{\delta_{\mathrm{s}}^{3}}{12 \mu} r \frac{\mathrm{d} p}{\mathrm{~d} r}\right)
$$

By substituting the boundary condition described in Eq. (22), Eq. (23) can be derived by the integration of Eq. (21) over the radius $r$. 


$$
\begin{gathered}
\begin{cases}r=r_{\mathrm{s}}, & p=p_{\mathrm{s}}, \\
r=R_{\mathrm{s}}, & p=p_{0},\end{cases} \\
p=\left(p_{\mathrm{s}}-p_{0}\right) \frac{\ln \left(r_{\mathrm{s}} / r\right)}{\ln \left(R_{\mathrm{s}} / r_{\mathrm{s}}\right)} \\
+\frac{3 \mu}{\delta_{\mathrm{s}}^{3}} \frac{\mathrm{d} \delta_{\mathrm{s}}}{\mathrm{d} t}\left[\left(r^{2}-r_{\mathrm{s}}^{2}\right)-\left(r_{\mathrm{s}}^{2}-R_{\mathrm{s}}^{2}\right) \frac{\ln \left(r_{\mathrm{s}} / r\right)}{\ln \left(R_{\mathrm{s}} / r_{\mathrm{s}}\right)}\right]+p_{\mathrm{s}},
\end{gathered}
$$

where $p_{\mathrm{s}}$ is the pressure of oil in slipper chamber. The second term on the right of Eq. (23) represents the pressure caused by the squeezing effect of the oil film. Based on Eq. (23), we can obtain

$$
\begin{aligned}
\frac{\mathrm{d} p}{\mathrm{~d} r}= & \frac{\left(p_{\mathrm{s}}-p_{0}\right)}{\ln \left(R_{\mathrm{s}} / r_{\mathrm{s}}\right)}\left(-r^{-1}\right)+\frac{3 \mu}{\delta_{\mathrm{s}}^{3}} \frac{\mathrm{d} \delta_{\mathrm{s}}}{\mathrm{d} t}(2 r) \\
& +\frac{3 \mu}{\delta_{\mathrm{s}}^{3}} \frac{\mathrm{d} \delta_{\mathrm{s}}}{\mathrm{d} t}\left(R_{\mathrm{s}}^{2}-r_{\mathrm{s}}^{2}\right) \frac{-r^{-1}}{\ln \left(R_{\mathrm{s}} / r_{\mathrm{s}}\right)}
\end{aligned}
$$

By substituting Eq. (24) into Eq. (12), Eq. (25) can be derived:

$$
\begin{aligned}
q= & \frac{\pi \delta_{\mathrm{s}}^{3}}{6 \mu} \frac{\left(p_{\mathrm{s}}-p_{0}\right)}{\ln \left(R_{\mathrm{s}} / r_{\mathrm{s}}\right)}-\pi r^{2} \frac{\mathrm{d} \delta_{\mathrm{s}}}{\mathrm{d} t} \\
& +\frac{\pi}{2} \frac{\left(R_{\mathrm{s}}^{2}-r_{\mathrm{s}}^{2}\right)}{\ln \left(R_{\mathrm{s}} / r_{\mathrm{s}}\right)} \frac{\mathrm{d} \delta_{\mathrm{s}}}{\mathrm{d} t} .
\end{aligned}
$$

The leakage flowing from slipper chamber to the pump case can be calculated from Eq. (25) by substituting the variable $r$ with the value of $r_{\mathrm{s}}$, as given by Eq. (26). The first term on the right of Eq. (26) represents the leakage flow caused by the differential pressure effect, and the second and third terms represent the leakage flow caused by the squeeze effect.

$$
\begin{aligned}
q= & \frac{\pi \delta_{\mathrm{s}}^{3}}{6 \mu} \frac{\left(p_{\mathrm{s}}-p_{0}\right)}{\ln \left(R_{\mathrm{s}} / r_{\mathrm{s}}\right)}-\pi r_{\mathrm{s}}^{2} \frac{\mathrm{d} \delta_{\mathrm{s}}}{\mathrm{d} t} \\
& +\frac{\pi}{2} \frac{\left(R_{\mathrm{s}}^{2}-r_{\mathrm{s}}^{2}\right)}{\ln \left(R_{\mathrm{s}} / r_{\mathrm{s}}\right)} \frac{\mathrm{d} \delta_{\mathrm{s}}}{\mathrm{d} t} .
\end{aligned}
$$

The variation of the flow rate caused by the change of volume of slipper chamber due to the squeezed oil film is given by

$$
q_{\mathrm{tem} 2}=\pi r_{\mathrm{s}}^{2} \frac{\mathrm{d} \delta_{\mathrm{s}}}{\mathrm{d} t}
$$

From Eqs. (26) and (27), the composite extrusion flow of slipper/swash plate pair caused by the squeeze effect of oil film can be derived as

$$
q_{\mathrm{se}}=\frac{\pi}{2} \frac{\left(R_{\mathrm{s}}^{2}-r_{\mathrm{s}}^{2}\right)}{\ln \left(R_{\mathrm{s}} / r_{\mathrm{s}}\right)} \frac{\mathrm{d} \delta_{\mathrm{s}}}{\mathrm{d} t}
$$

With Eqs. (14), (15), (19), and (28), the leakage flow via the clearance between the slipper and swash plate can be finally derived as

$$
\begin{aligned}
q_{\mathrm{ls}}= & \frac{\pi \delta_{\mathrm{s}}^{3} \Delta p_{\mathrm{s}}}{6 \mu \ln \left(R_{\mathrm{s}} / r_{\mathrm{s}}\right)}+\frac{\pi \rho \delta_{\mathrm{s}}^{3} \omega_{\mathrm{sm}}^{2}}{60 \mu}\left(R_{\mathrm{s}}^{3}-r_{\mathrm{s}}^{3}\right) \\
& +\frac{\pi}{2} \frac{\left(R_{\mathrm{s}}^{2}-r_{\mathrm{s}}^{2}\right)}{\ln \left(R_{\mathrm{s}} / r_{\mathrm{s}}\right)} \frac{\mathrm{d} \delta_{\mathrm{s}}}{\mathrm{d} t} \\
& +\int_{r_{\mathrm{s}}}^{R_{\mathrm{s}}} \int_{z=0}^{\delta_{\mathrm{s}}} \int_{\theta=0}^{\pi / 2} v_{\mathrm{or} 1} \mathrm{~d} r \mathrm{~d} z \mathrm{~d} \theta \\
& +\int_{r_{\mathrm{s}}}^{R_{\mathrm{s}}} \int_{z=0}^{\delta_{\mathrm{s}}} \int_{\theta=\pi / 2}^{\pi} v_{\mathrm{or} 2} \mathrm{~d} r \mathrm{~d} z \mathrm{~d} \theta \\
& +\int_{r_{\mathrm{s}}}^{R_{\mathrm{s}}} \int_{z=0}^{\delta_{\mathrm{s}} 3} \int_{\theta=\pi}^{3 \pi / 2} v_{\mathrm{or} 3} \mathrm{~d} r \mathrm{~d} z \mathrm{~d} \theta \\
& +\int_{r_{\mathrm{s}}}^{R_{\mathrm{s}}} \int_{z=0}^{\delta_{\mathrm{s}}} \int_{\theta=3 \pi / 2}^{2 \pi} v_{\mathrm{or} 4} \mathrm{~d} r \mathrm{~d} z \mathrm{~d} \theta .
\end{aligned}
$$

The output flow rate of pump is equal to the sum of the discharge flow of all piston/cylinder pairs of pump as

$$
Q_{\mathrm{o} 1}=\sum_{i=1}^{z_{\mathrm{p}}} q_{\mathrm{sp} i}
$$

where $z_{\mathrm{p}}$ stands for the number of pistons in the high-pressure discharge side of the pump. The flow rate via the throttling valve of throttling loading module portrayed in Fig. 1 can be determined by

$$
Q_{\mathrm{o} 2}=c_{\mathrm{q}} A_{\mathrm{tt}} \sqrt{\frac{2}{\rho} \Delta p_{\mathrm{t} 1}}
$$

where $c_{\mathrm{q}}$ is the flow coefficient, $A_{\mathrm{tl}}$ is the throttling area, and $\Delta p_{\mathrm{tl}}$ is the differential pressure. Due to fluid continuity and fluid compressibility of oil in the output pipeline between the output port of pump and the throttling valve, we can obtain

$$
Q_{\mathrm{o} 1}-Q_{\mathrm{o} 2}=\frac{V_{\mathrm{op}}}{K_{\mathrm{e}}} \frac{\mathrm{d} p}{\mathrm{~d} t}
$$


where $V_{\mathrm{op}}$ is the volume of oil in output pipeline between output port of pump and throttling valve. Finally, the fluid character of the pump can be represented by Eq. (33), derived from Eqs. (30)-(32):

$$
\frac{V_{\mathrm{op}}}{K_{\mathrm{e}}} \frac{\mathrm{d} p}{\mathrm{~d} t}+c_{\mathrm{q}} A_{\mathrm{tl}} \sqrt{\frac{2}{\rho} \Delta p_{\mathrm{tl}}}=\sum_{i=1}^{z_{\mathrm{p}}} q_{\mathrm{sp} i} .
$$

\section{Experimental}

A test bed to measure the efficiency and losses of pump was built, which is shown in Fig. 4. A typical axial piston pump widely used in the industry is chosen as the test pump, whose displacement is $90 \mathrm{~cm}^{3} / \mathrm{r}$, with the rated pressure of $35 \mathrm{MPa}$ and rated speed of $2100 \mathrm{r} / \mathrm{min}$. Experiments were carried out over a range of working conditions varying from $13 \%$ to $100 \%$ of full displacement, with four groups of speeds varying between 1000 and $2100 \mathrm{r} / \mathrm{min}$, as well as seven groups of pressure levels, from 5 to $35 \mathrm{MPa}$ in increments of $5 \mathrm{MPa}$.

The variable-displacement servo piston of test pump was fixed by the stopper bolt to control the displacement stably. The hydraulic oil in the circuit was exchanged by using an additional pump to control the oil temperature. Pressure sensors and pressure gages were mounted on the input port, output port, and the leakage drain pipeline of the pump to monitor the pressure; also flow sensors were mounted at theses points to monitor the flow rate. A speed sensor and a torque sensor were mounted on the driving shaft of pump to measure the input speed and torque of the pump. The speed of pump was adjusted by a variablefrequency motor. The load of the test pump was changed by adjusting the relief valve. The test data output by all the sensors with the standard signal were directly collected by the NI data acquisition card and transferred to the computer with the aid of data acquisition software. The volumetric losses $P_{\mathrm{Vtp}}$ and the hydro-mechanical losses $P_{\text {Mtp }}$ of test pump could be derived by Eqs. (34) and (35) from the measured data. The overall efficiency $\eta_{\mathrm{ov}}$, volumetric efficiency $\eta_{\mathrm{v}}$, and mechanical efficiency $\eta_{\mathrm{M}}$ can be calculated by Eqs. (36)-(38), respectively. The total leakage flow $q_{1}$ and compression flow $q_{\mathrm{cp}}$ of pump can be derived by Eqs. (39) and (40), respectively.

$$
\begin{gathered}
P_{\mathrm{Vtp}}=\left(Q_{\mathrm{i}}-Q_{\mathrm{o}}\right)\left(p_{\mathrm{lo}}-p_{\text {drain }}\right) \\
P_{\mathrm{Mtp}}=2 \pi T n-\left(p_{\mathrm{lo}}-p_{\mathrm{li}}\right) Q_{\mathrm{o}}-\left(p_{\mathrm{lo}}-p_{\text {drain }}\right)\left(Q_{\mathrm{i}}-Q_{\mathrm{o}}\right) \\
\eta_{\mathrm{ov}}=Q_{\mathrm{o}}\left(p_{\mathrm{lo}}-p_{\mathrm{li}}\right) /(2 \pi T n) \\
\eta_{\mathrm{V}}=1-\left(Q_{\mathrm{i}}-Q_{\mathrm{o}}\right) / Q_{\mathrm{i}} \\
\eta_{\mathrm{M}}=\eta_{\mathrm{ov}} / \eta_{\mathrm{v}} \\
q_{\mathrm{l}}=Q_{\text {drain }} \\
q_{\mathrm{cp}}=Q_{\mathrm{i}}-Q_{\mathrm{o}}-Q_{\text {drain }}
\end{gathered}
$$

where $Q_{\mathrm{i}}$ stands for the input flow rate of the pump, $Q_{\mathrm{o}}$ is the output flow rate, $p_{\mathrm{lo}}$ and $p_{\mathrm{li}}$ stand for the output port pressure and input port pressure, respectively, $p_{\text {drain }}$ is the drain pressure, $Q_{\text {drain }}$ is the leakage flow of pump, $T$ stands for the input torque, and $n$ is the speed.

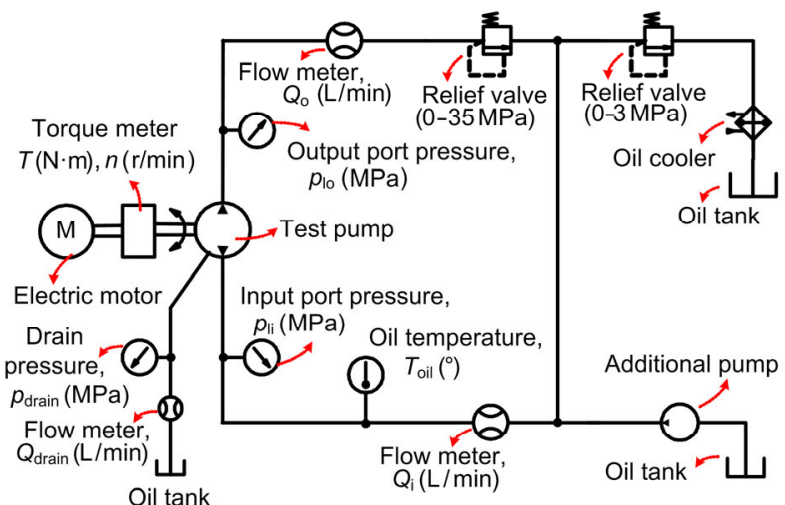

(a)

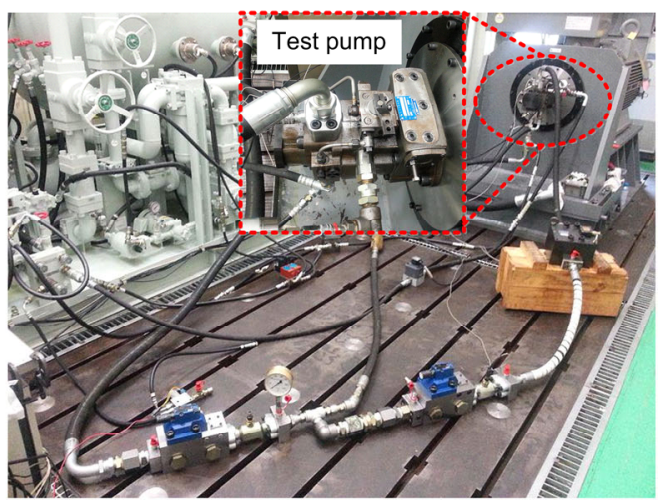

(b)

Fig. 4 Test circuit diagram (a) and test bed (b) 


\section{Results and discussion}

\subsection{Efficiency and comparison of losses}

As shown in Figs. 5 and 6, the maximum overall efficiency of the test pump at a speed of $2100 \mathrm{r} / \mathrm{min}$ and $1000 \mathrm{r} / \mathrm{min}$ can reach $90 \%$; nevertheless, with the decrease of displacement, the overall efficiency drops considerably. The highest overall efficiency of test pump can reach up to $90 \%$, which demonstrates that the test pump works very well. Comparison between Figs. 5 and 6 shows that, with the decrease of speed from the rated speed (i.e., $2100 \mathrm{r} / \mathrm{min}$ ) to $48 \%$ of the rated speed (i.e., $1000 \mathrm{r} / \mathrm{min}$ ), the low-efficiency area of pump increases significantly, gradually extending from low displacement conditions to large displacement conditions. Correspondingly, the high-efficiency area of the pump gradually decreases, and moves from the middle-high pressure conditions to middle-

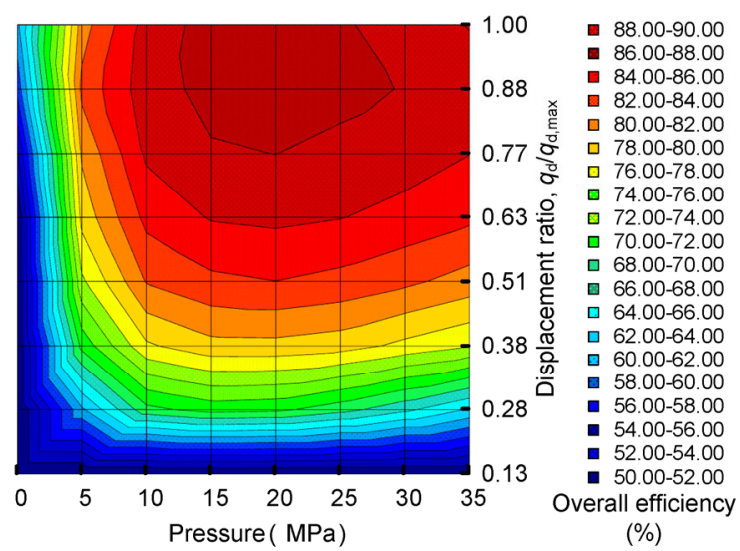

Fig. 5 Overall efficiency of pump measured by experiment at $2100 \mathrm{r} / \mathrm{min}$ pump speed

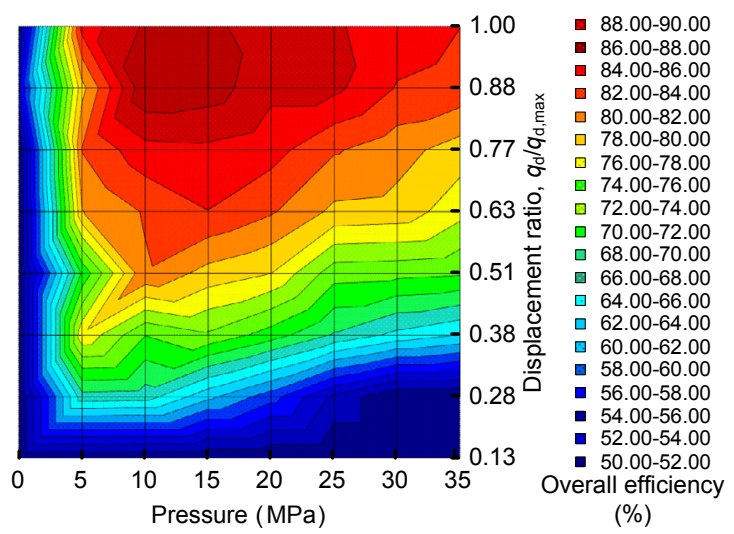

Fig. 6 Overall efficiency of pump measured by experiment at $1000 \mathrm{r} / \mathrm{min}$ pump speed low pressure conditions. In Figs. 5 and $6, q_{\mathrm{d}}$ and $q_{\mathrm{d} \text {,max }}$ stand for a certain displacement and the full displacement of pump, respectively.

Comparison between volumetric losses and the corresponding hydro-mechanical losses of pump at the rated speed of $2100 \mathrm{r} / \mathrm{min}$ is shown in Fig. 7. The volumetric losses are found to be generally lower than the hydro-mechanical losses over a wide operating range. At the conditions of high pressure ranging from 30 to $35 \mathrm{MPa}$ and large displacement ranging from $77 \%$ to $100 \%$ of full displacement, the volumetric losses can take the highest proportion, making up $47 \%$ of the pump's total power losses. After that, with the decrease of displacement or pressure, the proportion occupied by the volumetric losses gradually decreases. When the pressure decreases to $5 \mathrm{MPa}$ and the displacement decreases to $13 \%$ of the full displacement, the proportion of volumetric losses in the total power losses of pump drops to $13 \%$.

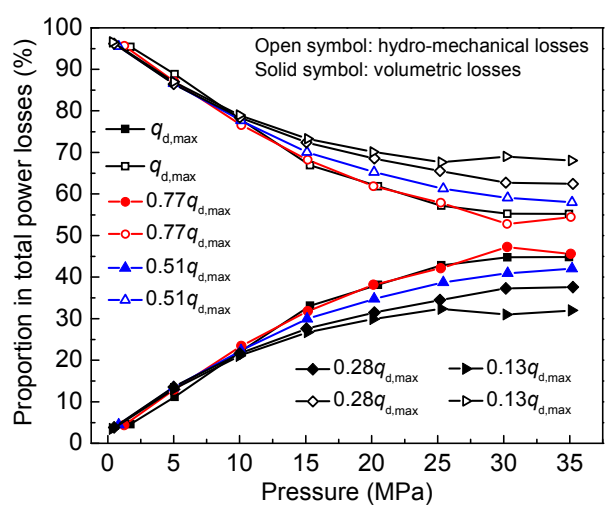

Fig. 7 Comparison of power losses of pump at the rated speed of $2100 \mathrm{r} / \mathrm{min}$ derived from the test data

Comparison of the proportion of leakage flow and compression flow in the total volumetric losses of pump at the rated speed of $2100 \mathrm{r} / \mathrm{min}$ is shown in Fig. 8. On the whole, the proportion of compression flow gradually decreases with the decrease of pressure or displacement. Under the condition of $13 \%$ of full displacement, the compression flow merely makes up several percent of the total volumetric losses. When the pressure is lower than $5 \mathrm{MPa}$ or the displacement is lower than $38 \%$ of full displacement, the proportion of compression flow is lower than $20 \%$. However, when the pressure is greater than $30 \mathrm{MPa}$ and the pump displacement is greater than $88 \%$ of full displacement, the highest proportion of compression 
flow losses in the total volumetric losses can reach up to $41 \%$.

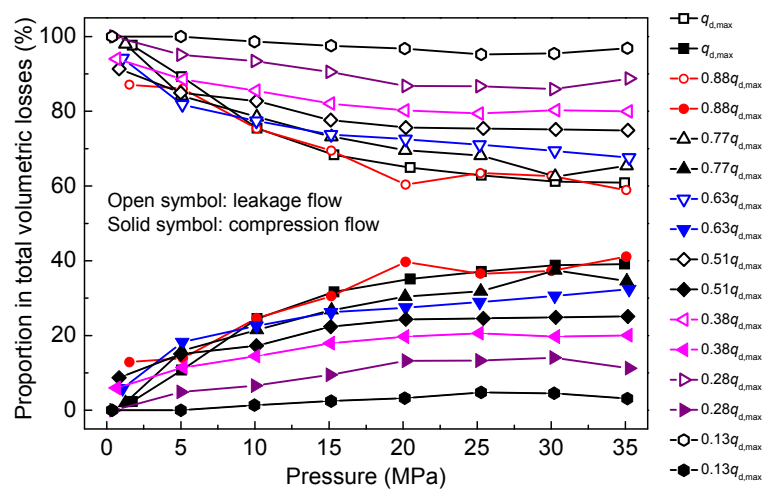

Fig. 8 Comparison between leakage flow and compression flow of pump at the rated speed of $2100 \mathrm{r} / \mathrm{min}$, derived from the test data

\subsection{Components analysis of leakage flow via the gap between slipper and swash plate}

To obtain explicit insight into the mechanism of leakage flow of the pump by the constructed model portrayed in Fig. 1, there are several parameters that are needed to be determined, for instance, the oil film depth, the eccentricity of piston in cylinder bore, the spin motion velocity of slipper, the squeeze velocity of oil film, etc. These parameters are hard to measure and depend upon the different transient working conditions of the pump. One of the available solutions is to use a verified implicit numerical program to find out the value of the parameters. The implicit numerical program models are built by using the Reynolds equation of lubrication, solved with the finite volume method (FVM), taking the influences of dynamic macro-motion and micro-motion of parts, the elastic deformation, the force equilibrium, and the pressureviscosity effect into consideration. The details are given in the previous studies of the authors (Xu et al., 2012; 2013).

The depth fields of oil film in piston/cylinder interface and slipper/swash plate interface are illustrated in Fig. 9. Generally, the depth fields are in non-uniform distribution. The angle axis in Fig. 9a stands for the angular position in circumferential direction around the piston, and the length ratio axis stands for the contact length ratio between the piston and bush.

To consider the impact of the non-uniform depth field of oil film on the leakage flow, the non-uniform depth field is considered as the mean depth at each angular position of the piston. The mean depth of oil film is the mean value of the depth of each discrete nodes of oil film field, as described in Eqs. (41) and (42), where $\delta_{\mathrm{pm}}$ and $\delta_{\mathrm{sm}}$ denote the mean depths of oil film of piston/cylinder pair and slipper/swash plate pair, respectively, $K_{\mathrm{p}}$ and $K_{\mathrm{s}}$ are the total numbers of discrete nodes of oil film field of piston/cylinder pair and slipper/swash plate pair, and $\delta_{\mathrm{p} k}$ and $\delta_{\mathrm{s} k}$ are the depths of the $k$ th discrete node of oil film field of the piston/cylinder pair and the slipper/swash plate pair, respectively. The discretization methods of oil film field of piston/cylinder pair and slipper/swash plate pair are introduced in detail in the previous studies undertaken by the present authors (Xu et al., 2012; $2013 ; 2015 c)$.

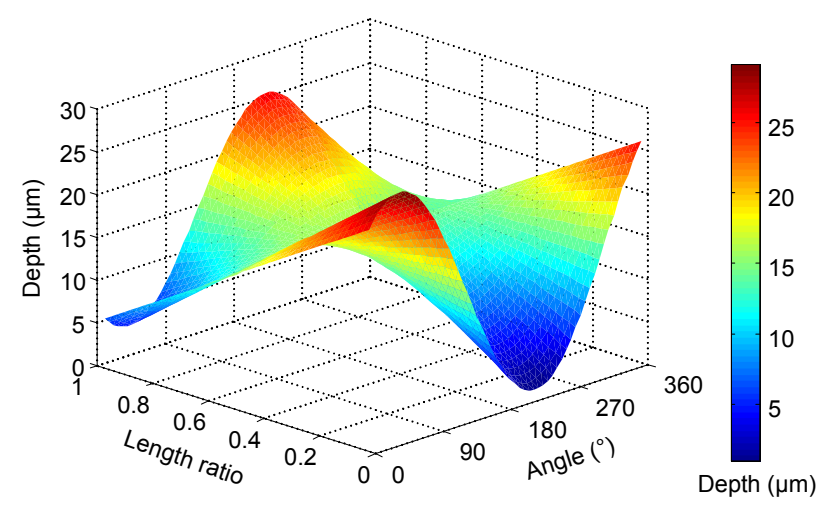

(a)

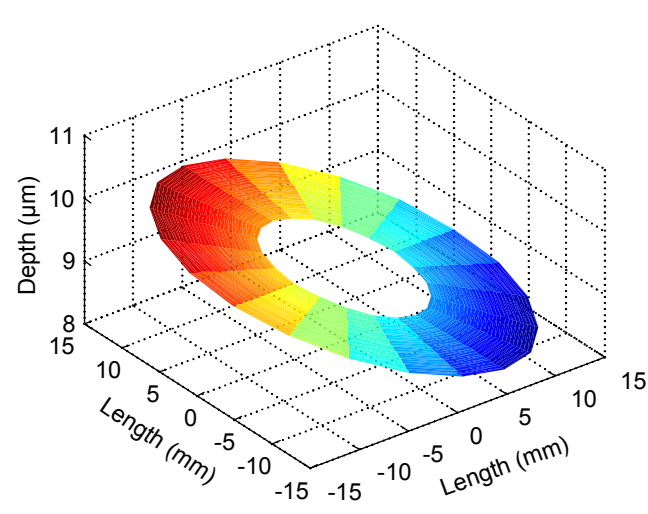

(b)

Fig. 9 Depth field of oil film obtained by simulation at $1500 \mathrm{r} / \mathrm{min}$ pump turning speed, 28 MPa pressure, and full displacement: (a) oil film of piston/cylinder pair, at the angular position of $159^{\circ}$ relative to the outer dead point of piston; (b) oil film of slipper/swash plate pair at the angular position of $21^{\circ}$ relative to the outer dead point of piston 


$$
\begin{aligned}
& \delta_{\mathrm{pm}}=\frac{1}{K_{\mathrm{p}}} \sum_{k=1}^{K_{\mathrm{p}}} \delta_{\mathrm{p} k}, \\
& \delta_{\mathrm{sm}}=\frac{1}{K_{\mathrm{s}}} \sum_{k=1}^{K_{\mathrm{s}}} \delta_{\mathrm{s} k} .
\end{aligned}
$$

The leakage of single slipper/swash plate pair is explicitly analyzed and shown in Fig. 10, consisting of four components: the Poiseuille flow caused by the differential pressure effect, the squeeze flow caused by the squeeze effect, the Couette flow caused by the spin motion, and the revolution motion of slipper. $q_{\mathrm{cs}}$ represents the leakage flow via the slipper/swash plate gap caused by the different effects discussed above. The spin motion velocity of slipper is approximately equal to the speed of the shaft, according to the experimental results measured by Fang and Ikeya (1992) and Tanaka et al. (2003). The squeeze velocity of slipper is shown in Fig. 11.

For a long time, in the conventional equation to calculate the leakage flow of slipper/swash plate pair, only the Poiseuille flow was considered. As Fig. 10 reveals, the Couette flow caused by the spin motion and revolution motion of slipper is much smaller than the Poiseuille flow and squeeze flow. Therefore, in the conventional calculation of leakage flow of slipper/swash plate pair, the Couette flow is allowed to be neglected. However, the result of calculation in Fig. 10 indicates that the squeeze flow might reach a magnitude equal to that of the Poiseuille flow. That means that squeeze flow should be taken into account when calculating the leakage flow of slipper/swash plate pair.

\subsection{Variation characteristics of volumetric losses with displacement of pump}

The mean depth of oil film and the inclined angle of piston or the overturning angle of slipper are the important factors reflecting the variation characteristics of leakage flow.

As shown in Fig. 12, the overturning angle $\alpha_{\mathrm{s}}$ of slipper can be calculated by Eq. (43), where $\delta_{\mathrm{s}, \max }$ and $\delta_{\mathrm{s}, \mathrm{min}}$ stand for the maximum and minimum values of the depth of oil film of slipper/swash plate pair,

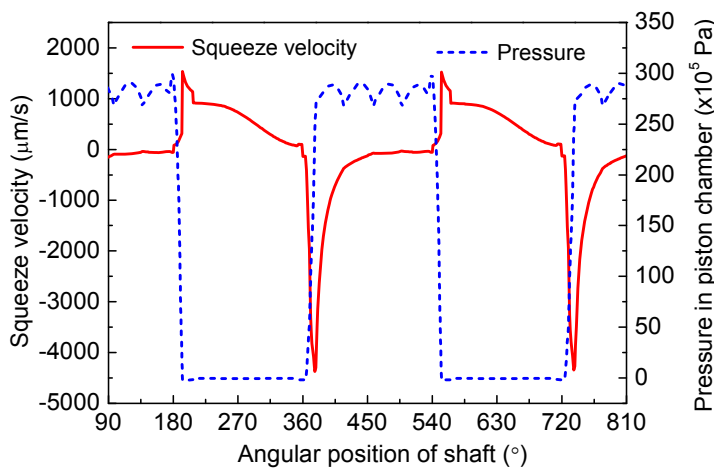

Fig. 11 Squeeze velocity of slipper obtained by simulation at $1500 \mathrm{r} / \mathrm{min}$ pump turning speed and full displacement

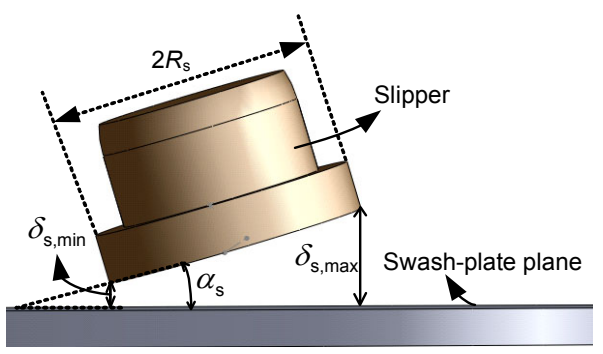

Fig. 12 Tilting state of slipper
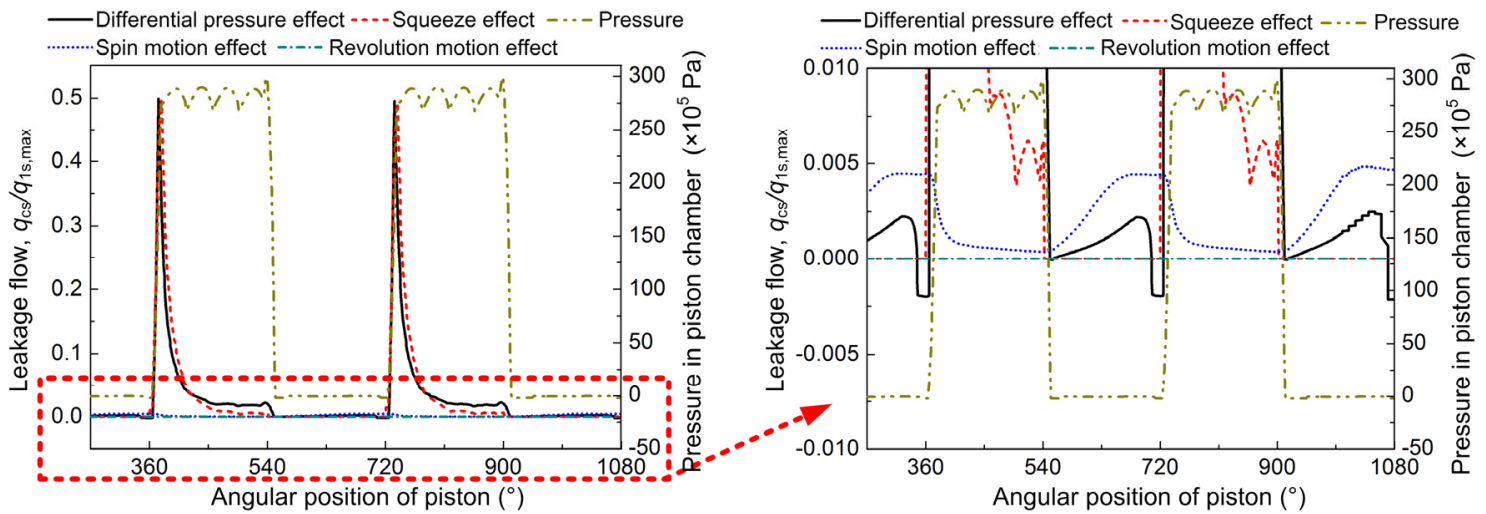

Fig. 10 Components analysis of leakage via the gap between slipper and swash plate obtained by simulation at $1500 \mathrm{r} / \mathrm{min}$ pump turning speed and full displacement $q_{\mathrm{ls} \text {,max }}$ represents the maximum instantaneous leakage flow via the slipper/swash plate gap 
respectively, which can be determined by the verified implicit numerical program developed in the previous study of the authors (Xu et al., 2012).

$$
\alpha_{\mathrm{s}}=\arcsin \frac{\delta_{\mathrm{s}, \max }-\delta_{\mathrm{s}, \min }}{2 R_{\mathrm{s}}} .
$$

As shown in Fig. 13, the inclined angle $\alpha_{\mathrm{p}}$ of piston can be calculated by Eq. (44), where $l_{\mathrm{f}}$ is the contact length between the piston and bush, and $e_{1}, e_{2}$, $e_{3}$, and $e_{4}$ are the eccentricity of piston section relative to cylinder bore at the position of the two end surfaces of bush, which can be determined by the verified implicit numerical program developed in the previous study of the authors (Xu et al., 2013).

$$
\alpha_{\mathrm{p}}=\arctan \frac{\sqrt{\left(e_{1}-e_{3}\right)^{2}+\left(e_{2}-e_{4}\right)^{2}}}{l_{\mathrm{f}}} .
$$

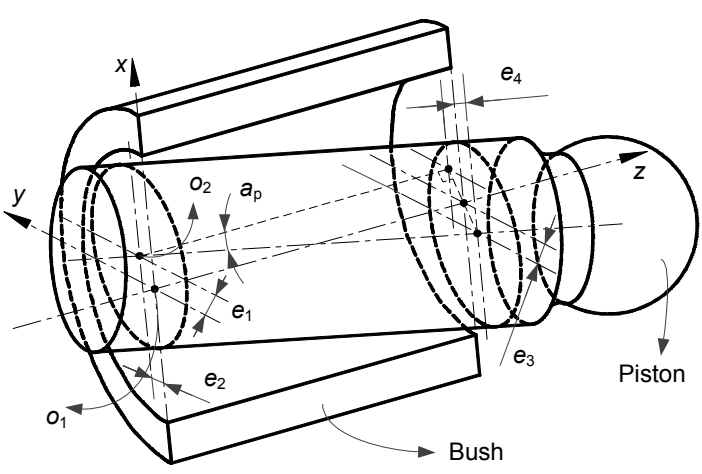

Fig. 13 Tilting state of piston in cylinder bore

Fig. 14 shows the variation of mean depth of oil film in the slipper/swash plate gap and the mean overturning angle of the slipper versus the displacement conditions of pump. With the decrease of displacement, the mean depth of the oil film increases, with a greater variation rate than the decrease rate of the overturning angle of slipper. According to Eq. (29), the variation of oil film depth and overturning angle finally yields the increase of leakage via the slipper/swash plate interface with the decreasing displacement of pump, as shown in Fig. 15, where $n_{\mathrm{r}}$ and $p_{\mathrm{r}}$ stand for the rated speed and the rated pressure, $\delta_{\mathrm{sd}, \mathrm{m}}, q_{\mathrm{lsd}, \mathrm{m}}$, and $\alpha_{\mathrm{sd}, \mathrm{m}}$ are the mean value of the oil film depth, the mean value of the leakage flow of slipper/ swash plate pair, and the mean overturning angle of slipper at a certain displacement condition, and $\delta_{\text {sd,max }}$, $q_{\text {lsd,max }}$, and $\alpha_{\text {sd,max }}$ are the maximum mean values of the oil film depth, the leakage flow of slipper/swash plate pair, and the overturning angle of slipper, respectively, under all the considered displacement conditions.

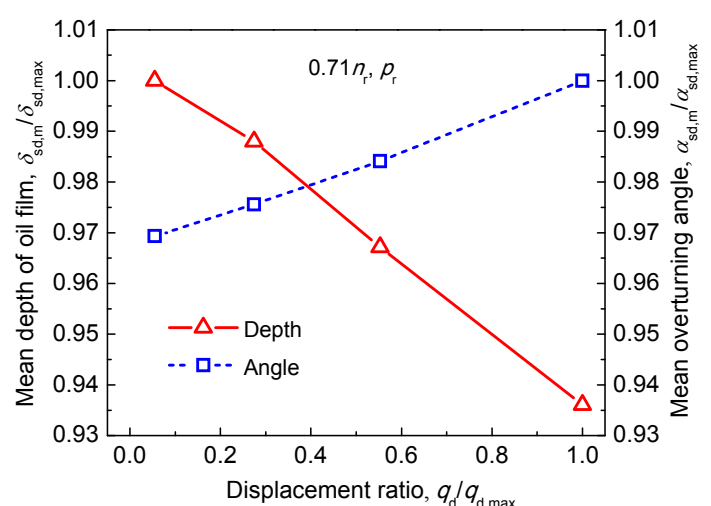

Fig. 14 Mean oil film depth of slipper/swash plate pair and overturning angle of slipper versus displacement obtained by simulation

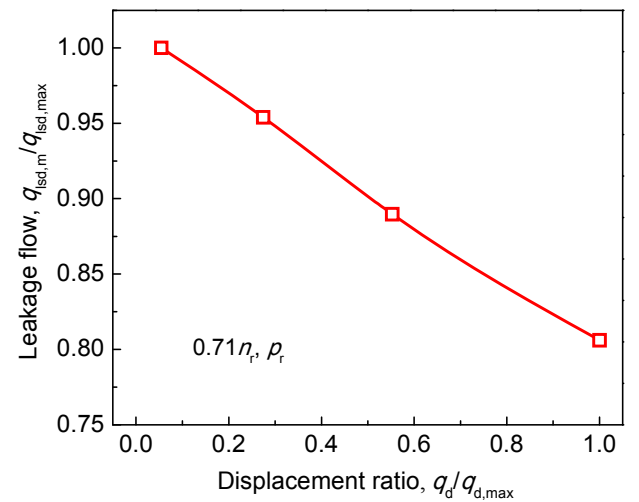

Fig. 15 Variation of leakage via slipper/swash plate gap versus pump displacement obtained by simulation

With the decrease of pump displacement, the variation of mean oil film depth of piston/cylinder pair and inclined angle of piston in cylinder bore are portrayed in Figs. 16 and 17, corresponding to the different pump speeds, where $\delta_{\mathrm{pd}, \mathrm{m}}$ and $\alpha_{\mathrm{pd}, \mathrm{m}}$ are the mean value of the oil film depth of piston/cylinder pair and the mean value of the inclined angle of piston at a certain displacement condition, and $\delta_{\mathrm{pd} \text {,max }}$ and $\alpha_{\mathrm{pd}, \max }$ are the maximum mean value of the oil film 
depth of piston/cylinder pair and the maximum mean value of the inclined angle of piston, respectively, under all the considered displacement conditions. At different speeds, the mean oil film depth of piston/ cylinder pair presents different variation trends; however, the inclined angle of the piston in the cylinder bore gradually decreases with the decreasing displacement.

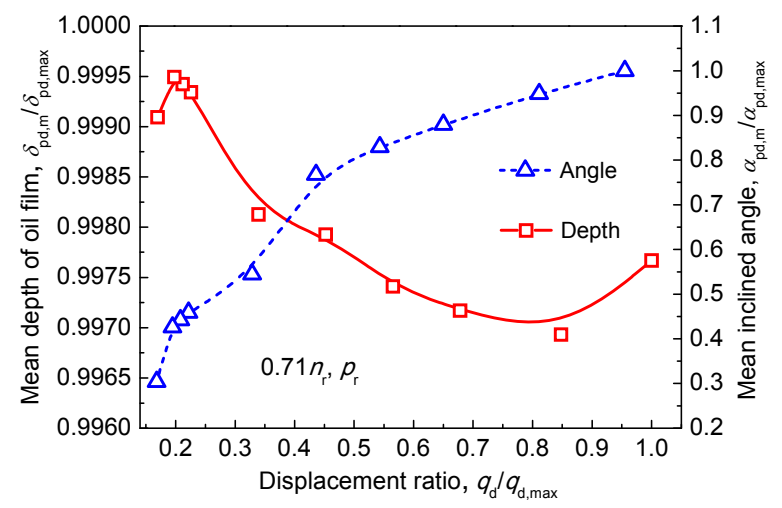

Fig. 16 Mean oil film depth of piston/cylinder pair and inclined angle of piston versus pump displacement obtained by simulation at $0.71 n_{\mathrm{r}}$

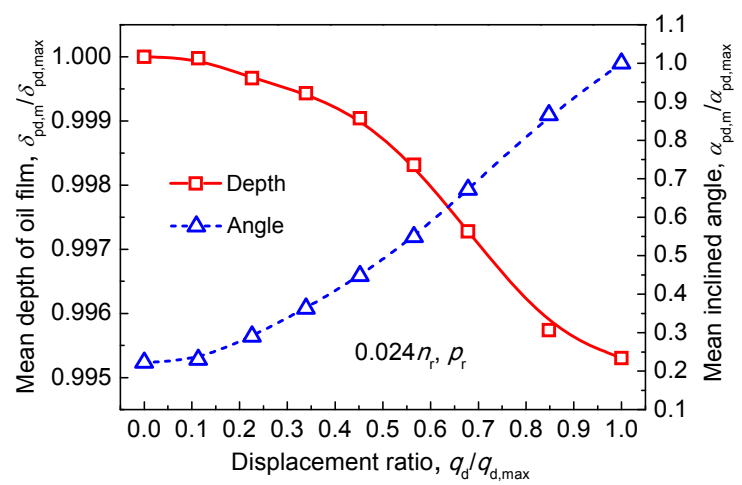

Fig. 17 Mean oil film depth of piston/cylinder pair and inclined angle of piston versus pump displacement obtained by simulation at $0.024 n_{\mathrm{r}}$

As described in Eq. (6), the leakage flow through the piston/cylinder interface is proportional to the cube of oil film depth and the square of the eccentricity of piston, represented by the inclined angle of piston in the cylinder bore. The variations of oil film depth and inclined angle of piston portrayed in Figs. 16 and 17 give rise to the leakage flow through the piston/cylinder interface shown in Fig. 18, where $q_{\text {lpd,m }}$ is the mean value of the leakage flow of piston/ cylinder pair at a certain displacement condition, and $q_{\text {lpd,max }}$ is the maximum mean value of the leakage flow of piston/cylinder pair under all the considered displacement conditions. At a relatively high speed of $71 \%$ of the rated speed, the corresponding leakage flow via the piston/cylinder interface first decreases with the decrease of displacement, and then increases with the further decrease of displacement. However, at a relatively low speed of $2.4 \%$ of rated speed, the leakage flow increases with decreasing displacement over the full range of the displacement conditions.

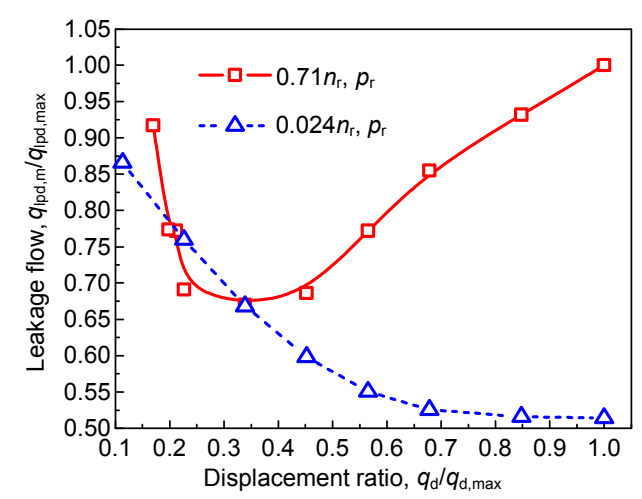

Fig. 18 Leakage flow of piston/cylinder pair versus pump displacement obtained by simulation

The typical variations of measured volumetric losses of pump versus displacement conditions are illustrated in Fig. 19. The compression flow is found to be almost proportional to the displacement of pump. However, Fig. 19 shows that the leakage flow takes on an increasing trend, with the displacement decreasing to a certain low displacement operating point. The leakage flow generally increases with the decrease of displacement, or may decrease with the decrease of displacement first, and then begin to increase after the minimum with the further decrease of displacement. The simulation-based variation trends of leakage flow illustrated in Figs. 15 and 18 are in accordance with the experimental variation trends of leakage.

However, it should be noticed that there are also a few exceptions that can be found at some operating points, as shown in Fig. 20. The compression flow is almost proportional to the displacement of pump, but the leakage flow first decreases with the decrease of 
pump displacement, and after the minimum, the leakage flow almost remains unchanged with further decrease of the pump displacement. The pulsation of leakage flow is mainly caused by the unstable actual pressure. It can be said that from the large number of measurement data, the few exceptions just indicate a

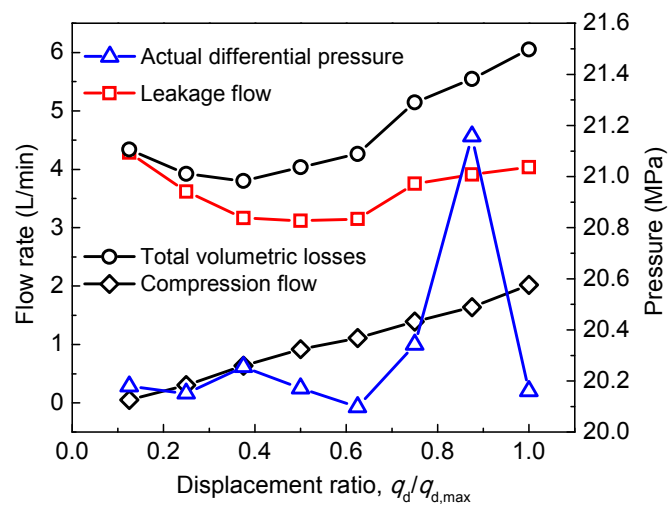

(a)

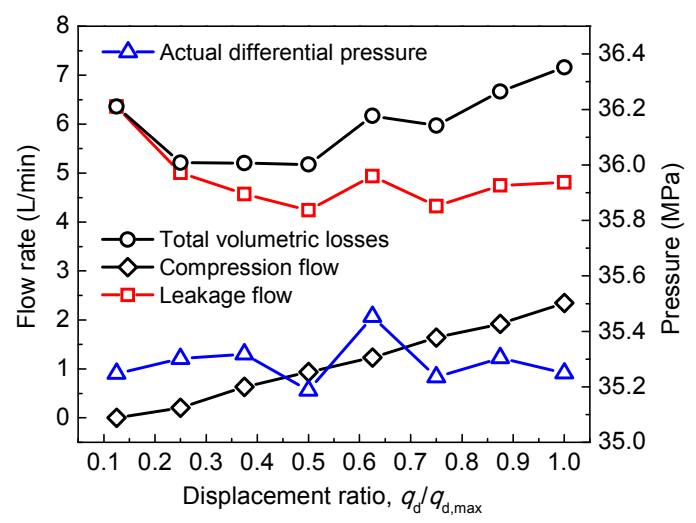

(b)

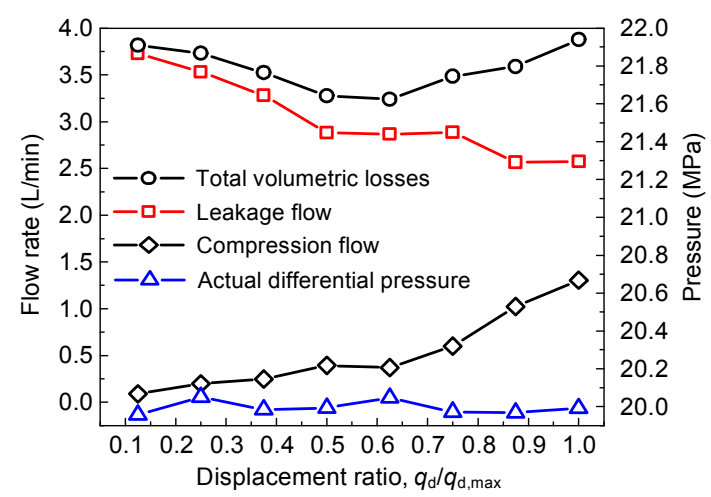

(c)

Fig. 19 Volumetric losses versus pump displacement (a) Under the conditions of $1700 \mathrm{r} / \mathrm{min}$ and $20 \mathrm{MPa}$; (b) Under the conditions of $1300 \mathrm{r} / \mathrm{min}$ and $35 \mathrm{MPa}$; (c) Under the conditions of $1000 \mathrm{r} / \mathrm{min}$ and $20 \mathrm{MPa}$

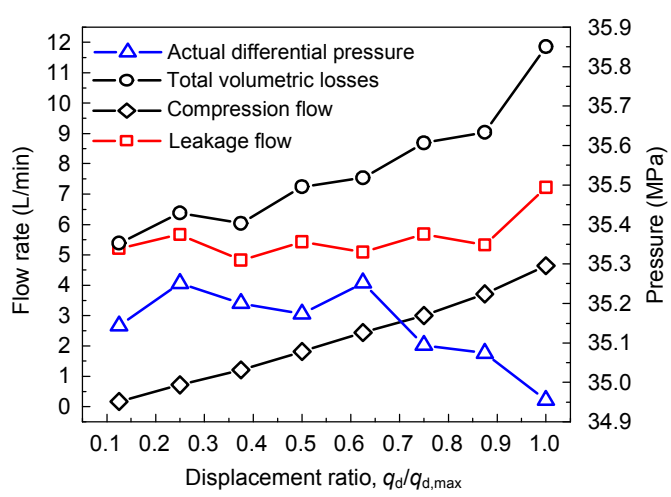

Fig. 20 Volumetric losses versus pump displacement under the conditions of $2100 \mathrm{r} / \mathrm{min}$ and $35 \mathrm{MPa}$

possible variation trend of leakage flow, but they cannot represent the general and typical variation characteristics of leakage flow with respect to displacement conditions, which are shown in Fig. 19.

\section{Conclusions}

In this study, a series of experiments were carried out to find the variation characteristics of efficiency, leakage, and compression flow of a pump over a wide operating range, especially for the displacement conditions. The mechanism of leakage via slipper/swash plate gap was further analyzed in detail by the proposed novel volumetric losses model, with a more complete equation to calculate the leakage via the slipper/swash plate gap. Compared with the previous models, the beauty of the novel model is that it allows explicit insight into the components of leakage flow. For the leakage of the slipper/swash plate pair, the squeeze leakage caused by the squeeze micromotion of the slipper is found to reach a magnitude equal to that of the Poiseuille flow caused by the differential pressure effect.

The overall efficiency of the pump is found to drop considerably with the decrease of displacement. With the speed decreasing from rated speed to $48 \%$ of the rated speed, the low-efficiency area of pump significantly increases. At the rated speed, the volumetric losses take a proportion ranging from $13 \%$ to $47 \%$ of the total power losses of pump, under the conditions of pressure ranging from 5 to $35 \mathrm{MPa}$ and pump displacement ranging from $13 \%$ to $100 \%$ of 
full displacement. The highest proportion of compression flow losses in the total volumetric losses of pump at the rated speed can reach up to $41 \%$ when the pressure is greater than $30 \mathrm{MPa}$ and the pump displacement is greater than $88 \%$ of full displacement. After that, generally the proportion gradually decreases with the decrease of displacement or pressure. When the pressure decreases to less than $5 \mathrm{MPa}$ or the displacement decreases to less than $38 \%$ of full displacement, the proportion decreases to less than $20 \%$.

The compression flow decreases with the decrease of displacement. However, the leakage flow generally increases with the decrease of displacement, or may decrease with the decreasing displacement first, and then begin to increase after the minimum with the further decrease of displacement.

\section{Acknowledgments}

The authors sincerely thank Senior Researchers Akira NAKAYAMA and Shohei RYU (Technical Research Center, Hitachi Construction Machinery Co., Ltd., Japan) for their constructive discussion and experimental assistance.

\section{References}

Bergada, J.M., Kumar, S., Davies, D.L., et al., 2012a. A complete analysis of axial piston pump leakage and output flow ripples. Applied Mathematical Modelling, 36(4): 1731-1751.

http://dx.doi.org/10.1016/j.apm.2011.09.016

Bergada, J.M., Davies, D.L., Kumar, S., et al., 2012b. The effect of oil pressure and temperature on barrel film thickness and barrel dynamics of an axial piston pump. Meccanica, 47(3):639-654.

http://dx.doi.org/10.1007/s11012-011-9472-7

Edge, K.A., Darling, J., 1989. The pumping dynamics of swash plate piston pumps. Journal of Dynamic Systems, Measurement, and Control, 111(2):307-312. http://dx.doi.org/10.1115/1.3153051

Ericson, L., Palmberg, J.O., 2012. Unsteady flow through a valve plate restrictor in a hydraulic pump/motor unit. Proceedings of 8th International Fluid Power Conference, IFK, Dresden, Germany, B6:1-13.

Fang, Y., Ikeya, M., 1992. Lubrication condition between the piston and cylinder for low-speed ranges of swashplate type axial pistons pump and motors: spin of the piston and its influence. Hydraulics \& Pneumatics, 23(4):420-426 (in Japanese). http://dx.doi.org/10.5739/jfps1970.23.420

Guan, C.H., Jiao, Z.X., He, S.Z., 2014. Theoretical study of flow ripple for an aviation axial-piston pump with damping holes in the valve plate. Chinese Journal of Aeronautics, 27(1):169-181.

http://dx.doi.org/10.1016/j.cja.2013.07.044

Huang, J.H., Quan, L., Zhang, X.G., 2014. Development of a dual-acting axial piston pump for displacementcontrolled system. Proceedings of the Institution of $\mathrm{Me}$ chanical Engineers, Part B: Journal of Engineering Manufacture, 228(4):606-616.

http://dx.doi.org/10.1177/0954405413506196

Ivantysyn, J., Ivantysynova, M., 2001. Hydrostatic Pumps and Motors. Academia Books International, New Delhi, India, p.130-133.

Kazama, T., 2008. Mixed lubrication simulation of hydrostatic spherical bearings for hydraulic piston pumps and motors. Journal of Advanced Mechanical Design, Systems, and Manufacturing, 2(1):71-82.

http://dx.doi.org/10.1299/jamdsm.2.71

Kumar, S., Bergada, J.M., 2013. The effect of piston grooves performance in an axial piston pumps via CFD analysis. International Journal of Mechanical Sciences, 66:168179.

http://dx.doi.org/10.1016/j.ijmecsci.2012.11.005

Lin, S., Hu, J.B., 2015. Tribo-dynamic model of slipper bearings. Applied Mathematical Modelling, 39(2):548-558. http://dx.doi.org/10.1016/j.apm.2014.06.009

Ma, J.E., Xu, B., Zhang, B., et al., 2010a. Flow ripple of axial piston pump with computational fluid dynamic simulation using compressible hydraulic oil. Chinese Journal of Mechanical Engineering, 23(01):45-52. http://dx.doi.org/10.3901/CJME.2010.01.045

Ma, J.E., Fang, Y.T., Xu, B., et al., 2010b. Optimization of cross angle based on the pumping dynamics model. Journal of Zhejiang University-SCIENCE A (Applied Physics \& Engineering), 11(3):181-190. http://dx.doi.org/10.1631/jzus.A0900417

Mandal, N.P., Saha, R., Sanyal, D., 2012. Effects of flow inertia modelling and valve-plate geometry on swash plate axial piston pump performance. Proceeding of the Institution of Mechanical Engineers, Part I: Journal of Systems and Control Engineering, 226(4):451-465. http://dx.doi.org/10.1177/0959651811426508

Manring, N.D., 2000. The discharge flow ripple of an axial piston swash plate type hydrostatic pump. Journal of Dynamic Systems, Measurement, and Control, 122(2): 263-268. http://dx.doi.org/10.1115/1.482452

Mizell, D., Ivantysynova, M., 2014. Material combinations for the piston-cylinder interface of axial piston machines: a simulation study. Proceeding of the 8th FPNI PhD Symposium, Lappeenranta, Finland.

Tanaka, K., Nakahara, T., Kyogoku, K., 2003. Half-frequency whirl of pistons in axial piston pumps and motors under mixed lubrication. Proceedings of the Institution of $\mathrm{Me}$ chanical Engineers, Part J: Journal of Engineering 
Tribology, 217(2):93-102.

http://dx.doi.org/10.1243/13506500360603633

Wegner, S., Gels, S., Murrenhoff, H., 2014. Simulation of the tribological contact cylinder block valve plate and influence of geometry and operating points on the friction torque in axial piston machines. 9th International Fluid Power Conference, Aachen, Germany, p.13-19.

Xu, B., Zhang, J.H., Yang, H.Y., 2012. Investigation on structural optimization of anti-overturning slipper of axial piston pump. Science China Technological Sciences, 55(11):3010-3018. http://dx.doi.org/10.1007/s11431-012-4955-x

Xu, B., Zhang, J.H., Yang, H.Y., et al., 2013. Investigation on the radial micro-motion about piston of axial piston pump. Chinese Journal of Mechanical Engineering, 26(2):325-333. http://dx.doi.org/10.3901/CJME.2013.02.325

Xu, B., Sun, Y.H., Zhang, J.H., et al., 2015a. A new design method for the transition region of the valve plate for an axial piston pump. Journal of Zhejiang UniversitySCIENCE A (Applied Physics \& Engineering), 16(3): 229-240. http://dx.doi.org/10.10.1631/jzus.A1400266

Xu, B., Ye, S.G., Zhang, J.H., 2015b. Effects of index angle on flow ripple of a tandem axial piston pump. Journal of Zhejiang University-SCIENCE A (Applied Physics \& Engineering), 16(5):404-417. http://dx.doi.org/10.10.1631/jzus.A1400309

Xu, B., Wang, Q.N., Zhang, J.H., 2015c. Effect of case drain pressure on slipper/swashplate pair within axial piston pump. Journal of Zhejiang University-SCIENCE A (Applied Physics \& Engineering), 16(12):1001-1014. http://dx.doi.org/10.10.1631/jzus.A1500182

Zecchi, M., Mehdizadeh, A., Ivantysynova, M., 2013. A novel approach to predict the steady state temperature in ports and case of swash plate type axial piston machines. Proceedings of the 13th Scandinavian International Conference on Fluid Power, Linkoping, Sweden.

\section{Appendix A: Derivation of Eq. (8)}

The following are the detail of the derivation procedure of Eq. (8) in the main text. Referring to a cylindrical coordinate system, in which the lubricating interface is defined in the $(r, \theta)$ plane, such that $z$ is the direction of the film thickness. The velocity in the direction of $\theta$-axis $v_{\theta}$ is determined by the following equation (A1), where $\omega$ is the angular velocity, $z$ is the thickness, $\delta_{\mathrm{s}}$ is the thickness of oil film.

$$
v_{\theta}=r \omega \frac{z}{\delta_{\mathrm{s}}}
$$

The lubrication theory allows the following assumptions to be made regarding fluid behavior in the thin film regime between slipper and swash plate:

1. Fluid inertial forces are small when compared with the viscous forces and can be negligible;

2. Steady state is assumed;

3. Body forces of the fluid are negligible;

4. Pressure is uniform along the film thickness $z$-axis direction. Similarly, fluid viscosity and density are assumed constant across the fluid film;

5. The fluid flows along the $r$-axis direction.

Based on these assumptions, the Navier-Stokes equation strongly reduces to

$$
\begin{aligned}
v_{r} \frac{\partial v_{r}}{\partial r} & -r \omega^{2} \frac{z^{2}}{\delta_{\mathrm{s}}^{2}}=-\frac{1}{\rho} \frac{\partial p}{\partial r} \\
& +v\left[\frac{\partial^{2} v_{r}}{\partial r^{2}}+\frac{1}{r} \frac{\partial v_{r}}{\partial r}+\frac{\partial^{2} v_{r}}{\partial z^{2}}-\frac{v_{r}}{r^{2}}\right],
\end{aligned}
$$

where $v$ is the kinematic viscosity of fluid film.

The fluid continuity equation reduces to

$$
\frac{\partial v_{r}}{\partial r}+\frac{v_{r}}{r}=0
$$

Integrating Eq. (A3) over the radius $r$ yields

$$
\frac{1}{r} \frac{\partial v_{r}}{\partial r}-\frac{v_{r}}{r^{2}}+\frac{\partial^{2} v_{r}}{\partial r^{2}}=0
$$

Substituting Eq. (A4) into Eq. (A2) yields

$$
\frac{1}{\mu} \frac{\partial p}{\partial r}=\frac{\partial^{2} v_{r}}{\partial z^{2}}+\frac{\rho \omega^{2} r z^{2}}{\mu \delta_{\mathrm{s}}^{2}}-\frac{\rho v_{r}}{\mu} \frac{\partial v_{r}}{\partial r}
$$

where dynamic viscosity $\mu=\rho v$. For the lubricating interface between slipper and swash plate, the following Eq. (A6) is true:

$$
\frac{\partial v_{r}}{\partial r} \ll \frac{\partial p}{\partial r} .
$$


Therefore, Eq. (A5) reduces to the following Eq. (A7), i.e., Eq. (8) in the main text:

$$
\frac{1}{\mu} \frac{\partial p}{\partial r}=\frac{\partial^{2} v_{r}}{\partial z^{2}}+\frac{\rho \omega^{2} r z^{2}}{\mu \delta_{\mathrm{s}}^{2}}
$$

\section{中文概要}

\section{题 目: 宽幅排量工况下轴向柱塞洜容积损失及效率变化} 特征

目 的：宽幅排量工况下高效率性能对于作为变排量洜控 节能系统动力源的柱塞洜至关重要, 而现有研究 对宽幅排量工况下原效率及各容积损失变化特 征的认识尚为不足。本研究探索并阐明泵效率、 容积损失（泄漏损失及压缩流量损失）及各损失 所占比重随排量工况的变化特征。

创新点: 1. 提出更完整的滑靴副泄漏计算方程, 建立显式 容积损失仿真模型, 发现由滑靴挤压微运动造成 的挤压泄漏的不可忽略性; 2. 揭示泵压缩流量、 泄漏流量及其造成的能量损失随排量工况的变 化特征。
方 法: 1. 基于纳维-斯托克斯方程及流体连续性方程, 推 导出更完整的滑靴副泄漏计算方程, 基于此方程 建立显式容积损失仿真模型； 2 . 在不同压力、转 速及排量工况组合下对原各损失进行 224 组大范 围工况下的大量实验测试; 3 . 基于仿真结果及实 验结果对宽幅排量工况下泵效率及各容积损失 变化特征进行分析讨论。

结 论: 1. 原总效率随排量减小显著下降; 2. 在额定转速 工况下，5 35 MPa 压力等级及 13\% 100\% 满排 量变化范围内, 洜容积损失在泵总损失中所占比 重在 $13 \%$ $47 \%$ 幅度内变化; 3 . 额定转速下泵压 缩流量损失在总容积损失中所占比重在 $30 \mathrm{MPa}$ 压力及 $88 \%$ 满排量等级以上时最高可达 $41 \%$, 此 后随着排量减小而逐渐减小, 当排量降至低于 $38 \%$ 满排量或压力降至低于 $5 \mathrm{MPa}$ 时, 压缩流量 损失在泵总容积损失中占比低于 $20 \% ; 4$. 压缩流 量随排量减小而减小, 而在绝大部分工况下, 泵 泄漏流量的典型变化特征是随着排量减小而逐 渐增大, 或先随着排量减小而减小, 但在当减小 到某一极小值时随着排量进一步的减小而逐渐 增大; 5. 由滑靴挤压微运动造成的滑靴副挤压泄 漏可以达到与由压差效应造成的滑靴副压差泄 漏相当的数量级。

关键词: 轴向柱塞泵; 效率; 泄漏; 压缩流量; 排量工况 